\title{
Exploring the relationship between spatiotemporal characteristics of snow cover and ENSO episodes over the Qinghai-Tibetan Plateau
}

\author{
Cungui Zhang ${ }^{\mathrm{a}, \mathrm{b}}$ (D), Fenggui Liu ${ }^{\mathrm{a}}$ and Yanjun Shen ${ }^{\mathrm{a}, \mathrm{b}}$

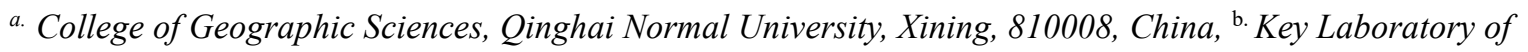 \\ Agricultural Water Resources, Center for Agricultural Resources Research, Chinese Academy of Sciences, \\ Shijiazhuang, 050021, China \\ Email: cungui.zhang@gmail.com
}

\begin{abstract}
The Qinghai-Tibetan Plateau as a vital water source is the largest area of snow cover in China. Recently, many relative studies presented evidence of a decreasing trend over the Qinghai-Tibetan Plateau snow cover area (SCA) in the last dozen years based on analysis of MODIS snow cover extent product satellite record. The main objectives of this study are to analyze the spatiotemporal characteristics of snow cover over the Qinghai-Tibetan Plateau, as well as to explore the relationship among climate variables and El Niño-Southern Oscillation (ENSO) episodes and SCA used MOD10C2 snow cover production. The SCA was derived from MOD10C2 and analyzing SCA trends through the Mann-Kendall statistical tests. Results indicated that no significant decreasing trend for SCA in the QTP from 2001 to 2016. In addition, trends of SCA over the QTP had spatial differences during the period 2001-2016, SCA of the Southern in the QTP had a decreasing trend while SCA of the Northern had an increasing trend. In the monthly scale, SCA expanded to the lower-altitude areas in the snow-accumulation period (March) while SCA shrunk to the higher-altitude areas in the snow-melt period (August). Generally, there was a negative correlation between decreasing SCA and significant increasing Temperature while a positive correlation between decreasing SCA and decreasing Precipitation. The result of correlation analysis showed that the La Niña years were coincident with larger SCA, while SCA of the El Niño years were lesser than of normal years over the QTP during the period 2001-2016.
\end{abstract}

Keywords: Spatiotemporal characteristics of SCA, relationship, ENSO episodes, Qinghai-Tibetan Plateau 
Zhang et al., Exploring the relationship between spatiotemporal characteristics of snow cover and ENSO episodes over the Qinghai-Tibetan Plateau

\section{INTRODUCTION}

The role of snow in energy exchange, climate change and water cycles has resulted in its recognition as an essential climate variable by the Global Climate Observation System (Gurung et al., 2017), because of its high albedo, thermal and water storage properties, can indicate the changes in global climate (Dozier et al., 2008; Foster et al., 2005; Liu and Chen, 2011; Wang and Li, 2006). Snow cover is strongly dependent on atmospheric temperature and precipitation, and is likely to change climate in complex ways. In addition, the snow cover response to climate warming could therefore vary with latitude and elevation, with potential for increased accumulation in high latitudes and high elevations where increases in precipitation are sufficient to offset reductions in the length of the accumulation season (Brown and Mote, 2009). Räisänen (2008) also documented that the snow cover response to global warming was complicated by projected increases in precipitation, particularly over high latitudes.

The Qinghai-Tibet Plateau (QTP) is the source of major river systems in Asia, Ganges, Brahmaputra, Yangtze, Yellow and Mekong and provide freshwater resources to over 1.4 billion people in this region, for which reason also being called as the Asian Water Towers (Immerzeel et al., 2010). Meanwhile, the unique interactions among the atmosphere, cryosphere, hydrosphere and biosphere on the Third Pole ensure permanent flow of Asia's major rivers (Qiu, 2008; Yao et al., 2012). Snow and ice are main land cover type over the QTP except with grasslands and barren, these regions are very susceptible to climate change (Maskey et al., 2011). Therefore, the study area also demonstrates considerable feedbacks to global environmental changes. In addition, the QTP plays a fundamental role in the formation and maintenance of the summer circulation over Asia, and it is also an important mechanism influencing the formation of the Asian monsoon (Ruddiman and Kutzbach, 1991; An et al., 2001).

Many of the studies on snow cover area (SCA) changes and variability were done in the world, however, the research results exist difference in different region. For the QTP region, Snehmani et al. (2016)studied the 2001-2012 winter period (November-April) in order to obtain clear negative snow cover trends in the basin. Azmat et al. (2017) indicated that the watershed shows a consistent or slightly decreasing trend of snow cover, particularly over the high-altitude parts of the watershed during 2000-2009, and in the 14-year analysis (2000-2013), a slight expansion in the snow-covered area was observed in the whole basin. Gurung et al. (2017), based on the analysis SCA data between 2003 and 2012, also obtained a decline in SCA, with a statistically significant negative correlation between SCA and temperature, which indicates that this trend is partly a result of increasing temperatures.

The objective of the study is to evaluate the spatiotemporal dynamics of the SCA in the QTP, and to analyze its relationship with climate variables and El Niño-Southern Oscillation (ENSO) events. We investigated trends and variability of snow cover changes at different temporal scales (monthly and annual) and we used MODIS10C2 snow cover products (Hall et al., 2015) from 2000 to 2017.

\section{MATERIALS AND METHODS}

\subsection{Study area}

The Qinghai-Tibetan Plateau (QTP) is the highest and largest plateau in the world with an average elevation of $\sim 4000 \mathrm{~m}$ above sea level, which is a unique geomorphic unit composed of some basic geomorphic types, such as extremely high mountains, high mountains, hills, plains, and tablelands of high altitudes or sub-high altitudes.

It sits at a longitude of 31 degrees with a length of $2945 \mathrm{~km}$ from east to west, and sits at a latitude of 13 degrees with a length of $1532 \mathrm{~km}$ from south to north. With a range of $26^{\circ} 46^{\prime} 00^{\prime} 12$ " $39^{\circ} 50^{\prime} \mathrm{N}, 73^{\circ} 18^{\prime} 52^{\prime} \sim 104^{\circ} 46^{\prime} 59^{\prime \prime} \mathrm{E}$, the QTP covers an area of approximately $2.57 \times 10^{6} \mathrm{~km}^{2}$, accounting for $26.8 \%$ of the total land area in China (Zhang et al., 2002) (Fig.1).

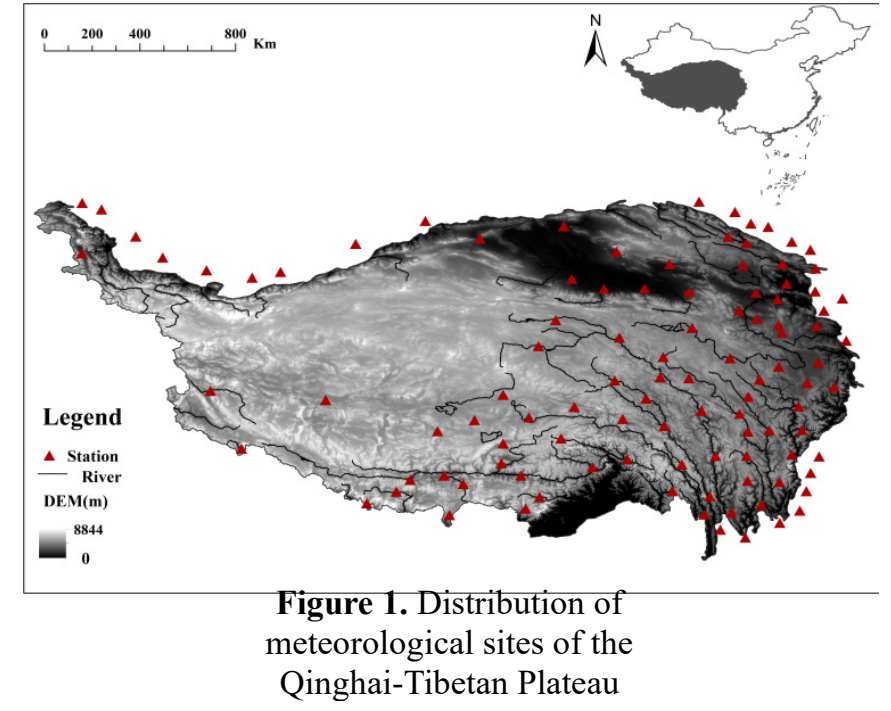


Zhang et al., Exploring the relationship between spatiotemporal characteristics of snow cover and ENSO episodes over the Qinghai-Tibetan Plateau

\subsection{Materials}

\subsubsection{MODIS snow cover production}

The MOD10CM SCP data is generated from Normalized Difference Snow Index (NDSI) snow cover (Hall et al., 2015). This data set reports monthly average snow cover in 0.05 degree (approx. $5 \mathrm{~km}$ ) resolution Climate Modeling Grid (CMG) cells. Monthly averages are computed from daily snow cover observations in the MODIS/Terra Snow Cover Daily L3 Global 0.05Deg CMG (MOD10C1) data set. Version 6 (also known as Collection 6) is the most recent version of MODIS snow cover data available from NSIDC.

\subsubsection{In situ Meteorological data}

In this study, the data used were collected from 105 ground-based meteorological stations operated by the China Meteorological Administration. These stations have complete records of almost all climatic factors from Jan. 2000 to Mar. 2017, including monthly observations of average temperature and precipitation.

\subsubsection{ENSO and NAO index}

The historical data from El Niño/La Niña-Southern Oscillation (ENSO) episodes from Jan. 2000 to Mar. 2017 from the NOAA Official website:

(http://www.cpc.noaa.gov/products/analysis monitoring/ensostuff/ensoyears.shtml). Normal or neutral years correspond to historical conditions, as Niño and Niña years correspond to warm/wet and cold/dry years, respectively. The historical data from Southern Oscillation Index (SOI) from Jan. 2000 to Mar. 2017 (http://www.bom.gov.au/climate/current/soi2.shtml). The historical data from Arctic Oscillation Index (AOI) from Jan. 2000 to Mar. 2017 (http://www.cpc.noaa.gov/products/precip/CWlink/daily ao index/ao.shtml), refers to variations in the difference in the atmospheric pressure patterns between northern mid-latitudes (about 45 degrees North) and the Arctic.

\subsection{Methods}

In this study, the simple linear regression and a non-parametric Mann-Kendall trend test was applied to determine the existence of monotonic trends. The Mann-Kendall Trend Test (sometimes called the M-K test) is used to analyze data collected over time for consistently increasing or decreasing trends.

\section{RESULTS}

\subsection{Spatial-temporal characteristics of SCP}

Snow mainly accumulate on the large mountains. Fig. 2 shows that snow mainly distributed in the high-altitude areas in the QTP, such as the Himalayas Mt., the Kunlun, the Gangdise, the Qilian and the Hengduan Mts. Above results indicate that the high mountains are more easily accumulate snow than the low-altitude valley regions. The early lots of literatures (Mountain Research Initiative EDW Working Group, 2015; Maskey et al., 2011) have reported that distribution of snow accumulation generally influenced by topography factors such as elevation, step, slope, aspect and so on.

Trend analysis showed that spatial variability of SCP was different over the QTP, of which SCP with lower-latitude regions showed a significant decreasing trend while SCP with higher-latitude regions showed an indistinctively increasing trend. However, no trend in most of areas over the QTP.

Fig. 3 shows distribution of the statistic multi-year average SCP for March and August in the QTP for 16 years. After comparison by two months (March and August), it is clearly see that high-SCP (> 50\%) for March obviously larger than August. In addition, the statistic multi-year average monthly data show SCA derived from FSC for March is largest $\left(59.35 \times 10^{4} \mathrm{~km}^{2}\right)$ while one for August is smallest $\left(11.13 \times 10^{4} \mathrm{~km}^{2}\right)$ in the QTP (Fig. 4).

But beyond that, there was large difference between spatial pattern of SCP for March and August. Distribution extent of High-SCP $(>50 \%)$ for March was larger than August, that is, snow cover altitude was lower than August thanks to effect of season, topography and other uncertain factors. Distribution pattern of SCP for March was consistent with the multi-year average one, while distribution pattern of SCP for August was completely different compared to the previous two pattern. 


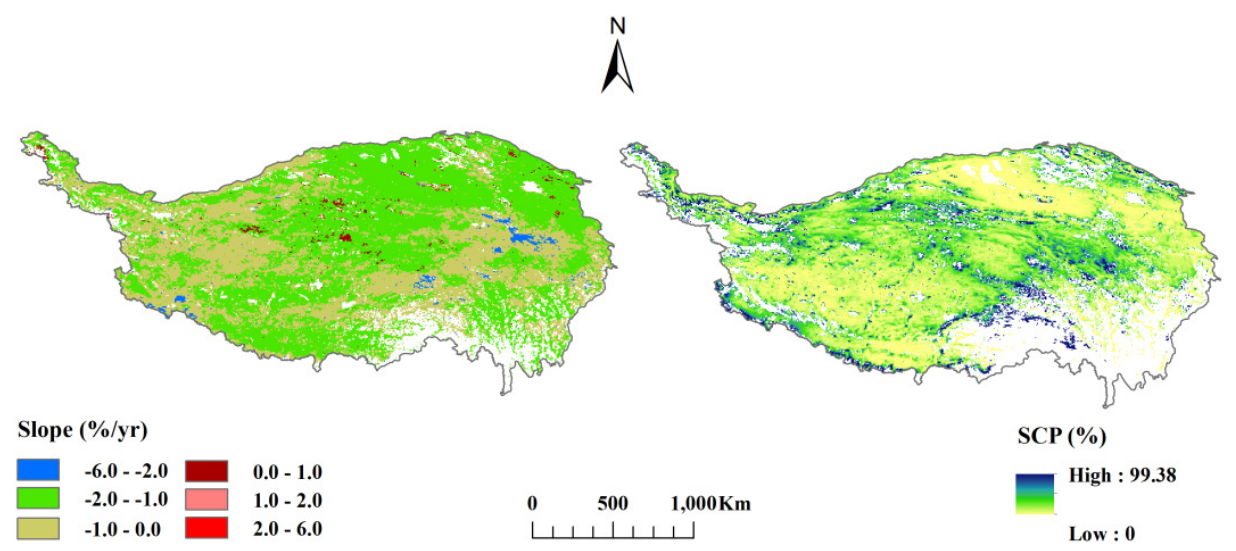

Figure 2. Distribution and trends of SCP in the QTP from 2001 to 2016

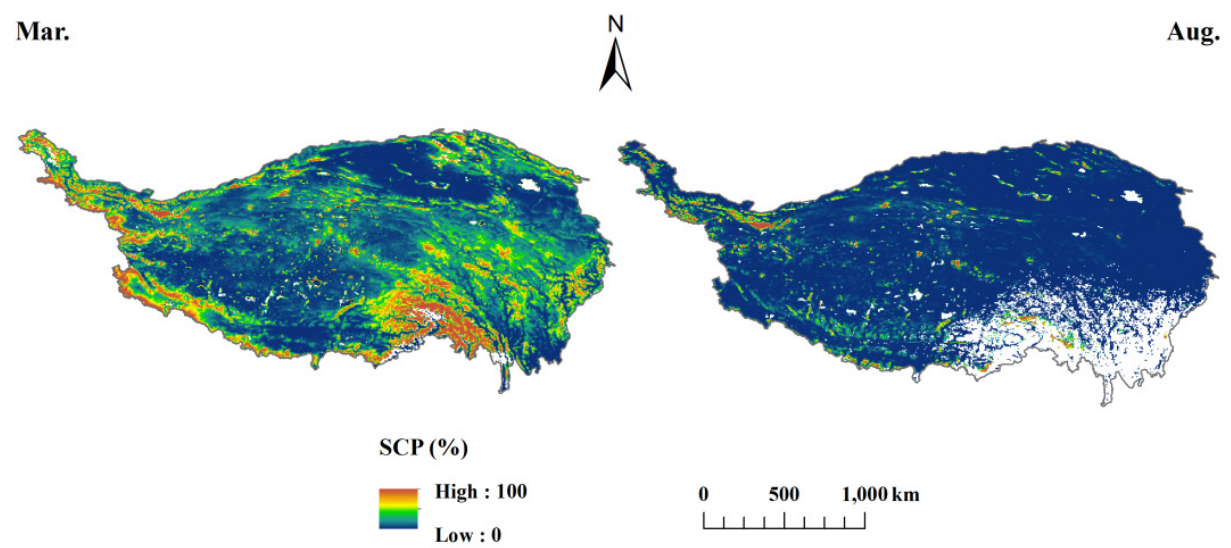

Figure 3. Spatial pattern of SCP for Mean March (snow-accumulation month) and Mean August (snow-melt month) in the QTP from 2001 to 2016

Annual SCA no significant decreasing trend with $-1.98 \times 10^{4} \mathrm{~km}^{2} / 10 \mathrm{a}$ by M-K trend test $(\mathrm{a}=0.05)$ in the QTP from 2001 to 2016 (Fig. 4). In annual fluctuation, the maximum of SCA was $45.90 \times 10^{4} \mathrm{~km}^{2}$ in 2005 while the minimum was $32.34 \times 10^{4} \mathrm{~km}^{2}$ in 2016 .
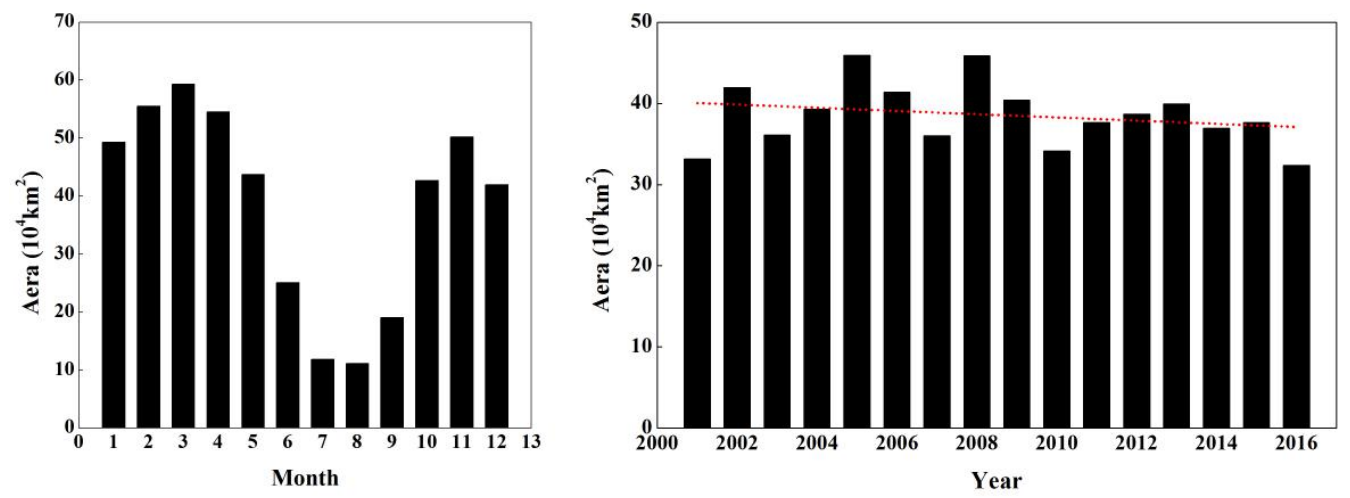

Figure 4. Characteristics of inner-annual and inter-annual SCA in the QTP from 2001 to 2016 (The red dotted line indicate trend line)

\subsection{Correlation between SCA and climate variables}

At the inter-annual scale, there is markedly change that correlations between SCA and climate variables (Fig. 5). Above mentioned trend of SCA no significant decreasing trend, Temperature had a significant increasing trend at a level of significance $\leq 0.05$ with a slope of $0.46{ }^{\circ} \mathrm{C} / 10 \mathrm{a}$ in the QTP from 2001 to 2016 . However, Precipitation had an insignificant decreasing trend at a level of significance $\leq 0.05$ with a slope of 2.86 $\mathrm{mm} / 10 \mathrm{a}$ in the QTP from 2001 to 2016 . Thus, there is a negative correlation between SCA and Temperature, 
while we found a positive correlation between SCA and Precipitation at the inter-annual scale in the QTP during the period 2001-2016.

\subsection{The possible connections between SCA and ENSO episodes}

At the inter-annual scale, there is certain relations between SCA and fluctuation of SOI and AOI to a certain extent. Fig. 6 shows that there are positive correlation between SCA and fluctuation of SOI and AOI during some year points, but negative correlation among variables during other year points.

In order to further analyze the possible reasons causing change of SCA, we adopt
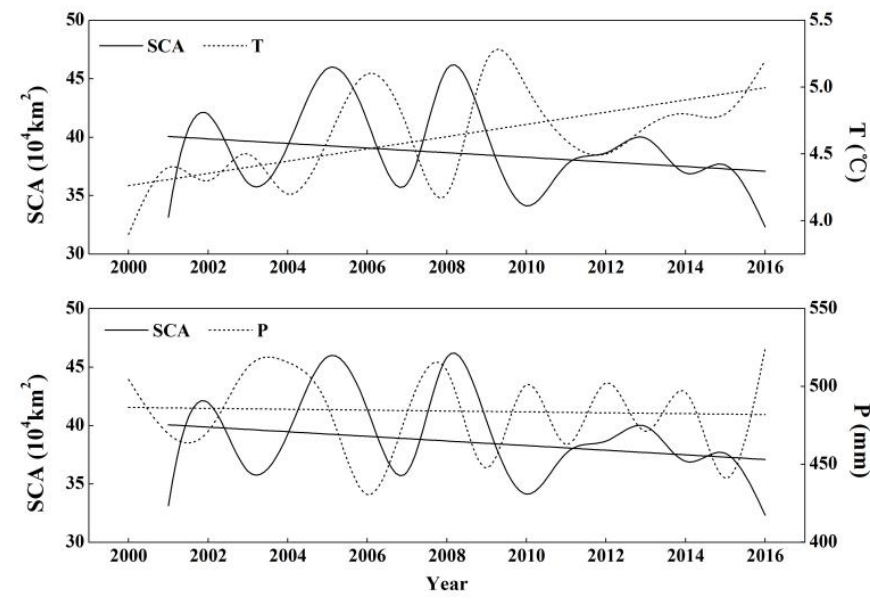

ENSO index to exploring correlation between SCA and ENSO episode in the inter-annual scale, respectively.

During the period of 2000-2016, the SCA in the QTP was contrasted with historical data from El Niño/La Niña-Southern Oscillation (ENSO)

Figure 5. Correlations between SCA and climate variables

episodes. Normal or neutral years correspond to

historical conditions, as El Niño and La Niña years correspond to warm and cold years over QTP, respectively. There were five episodes of El Niño (2002, 2004-2005, 2006-2007, 2009 and 2015-2016) and three episodes of La Niña (1999- 2000, 2007-2008 and 2010-2011) occurred from 2000 to 2016 (Fig.7 and Fig.8).
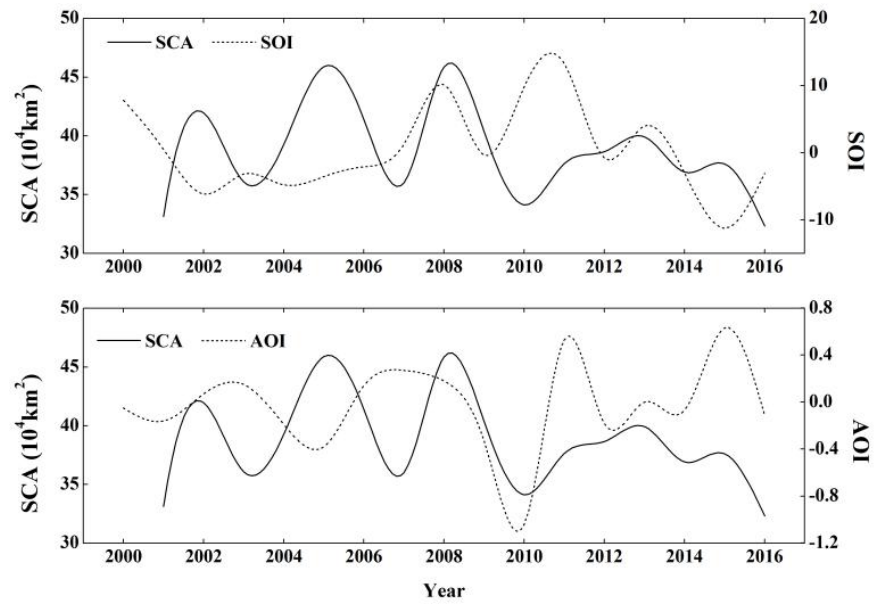

Figure 6. Correlations between SCA and SOI and AOI in the QTP from 2001 to 2016

Fig. 7 shows that correlations between ENSO for 212 months in the QTP during the period of 2000-2017. During the La Niña months, SCA was clearly larger than normal and El Niño months, such as 2007 and 2010. Especially, the La Niña event of 2007 was coincident with the SCA in the QTP during the study period of 2000-2016. Meanwhile, SCA was not very visibly smaller than normal and La Niña months during the El Niño months, but the El Niño event of 2016 was coincident with the SCA in the QTP during the study period of 2000-2016.

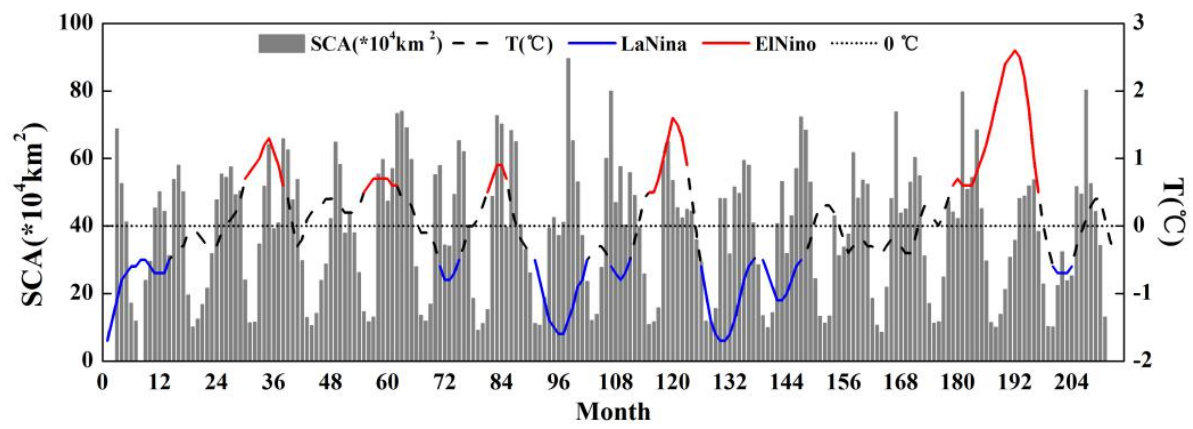

Figure 7. Correlations between ENSO for 212 months in the QTP from 2000 to 2017 
Fig. 8 shows that correlations between ENSO in the QTP from 2000 to 2016 in the inter-annual scale. Significant congruent relation between annual SCA and ENSO episodes, such as the 2008 La Niña event was coincident with the SCA for the study period (2000-2016) in the QTP. Same with the monthly event, SCA for the El Niño years generally was smaller than La Niña years.

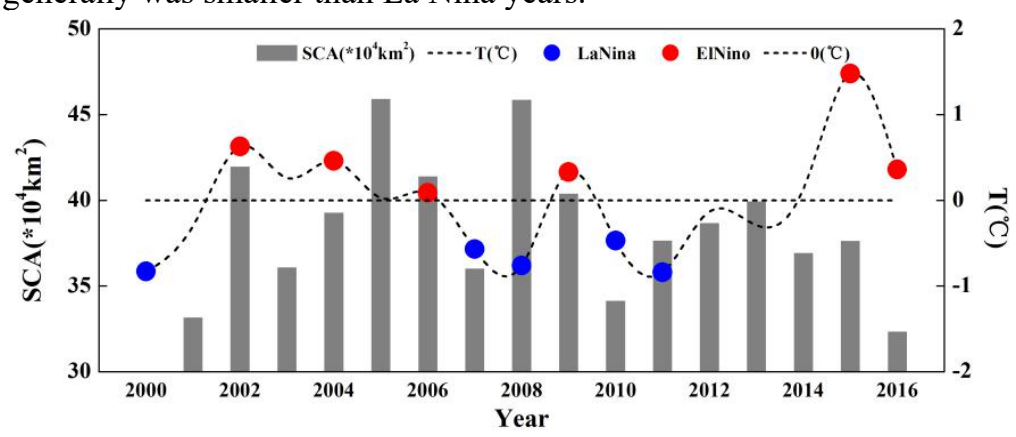

Figure 8. Correlations between ENSO in the QTP from 2000 to 2016

\section{CONCLUSIONS}

Trends in SCA over the QTP had spatial differences during the period 2001-2016, SCA for the Southern of QTP had a decreasing trend while SCA of the Northern has an increasing trend.

In general, there was significant spatial differences of monthly SCA during the period 2000-2017, SCA expanded to the lower-altitude areas in the snow-accumulation period (March) while SCA shrunk to the higher-altitude areas in the snow-melt period (August). In the process of trend analysis for SCA and climate variables, we found that there was a negative correlation between decreasing SCA and significant increasing temperature while a positive correlation between decreasing SCA and decreasing Precipitation. Cited the ENSO episode during 2000-2016, we tried to exploring the possible correlation between SCA and El Niño/La Niña events. Results showed that the La Niña years were coincident with larger SCA, SCA of the El Niño years were lesser than of normal years during the period 2001-2016 over the QTP.

Acknowledgments: The work was funded by China Scholarship Council (CSC), this study is a result of the Second Comprehensive Scientific Expedition to the Qinghai-Tibet Plateau.

\section{REFERENCES}

An, Z., Kutzbach, J.E., Prell, W.L., Porter, S.C., 2001. Evolution of Asian monsoons and phased uplift of the Himalaya-Tibetan plateau since Late Miocene times. Nature, 411(6833): 62-66.

An, Z., Kutzbach, J.E., Prell, W.L., Porter, S.C., 2001. Evolution of Asian monsoons and phased uplift of the Himalaya-Tibetan plateau since Late Miocene times. Nature, 411(6833): 62-66.

Azmat, M. et al., 2016. Hydrological modeling to simulate streamflow under changing climate in a scarcely gauged cryosphere catchment. Environmental Earth Sciences, 75(3): 186. DOI: $10.1007 / \mathrm{s} 12665-015-5059-2$.

Azmat, M. et al., 2017. Impacts of changing climate and snow cover on the flow regime of Jhelum River, Western Himalayas. Regional Environmental Change, 17(3): 813-825. DOI:10.1007/s10113-016-1072-6.

Brown, R.D. and Mote, P.W., 2009. The Response of Northern Hemisphere Snow Cover to a Changing Climate. Journal of Climate, 22(8): 2124-2145. DOI:10.1175/2008jcli2665.1.

Dozier, J. et al., 2008. Time-space continuity of daily maps of fractional snow cover and albedo from MODIS. Adv. Water Res. DOI:https://doi.org/10.1016/j.advwatres.2008.08.011.

Foster, J.L. et al., 2005. Quantifying the uncertainty in passive microwave snow water equivalent $\begin{array}{lllll}\text { observations. } & \text { Remote } & \text { Sens. } & \text { Environ. }\end{array}$ DOI:https://doi.org/10.1016/j.rse.2004.09.012.

Gurung, D.R. et al., 2017. Climate and topographic controls on snow cover dynamics in the Hindu Kush Himalaya. Int. J. Climatol. , 37(10): 3873-3882. DOI:10.1002/joc.4961.

Hall, D.K. and Riggs, G.A., 2015. MODIS/Terra Snow Cover Monthly L3 Global 0.05Deg CMG, Version 6. [Indicate subset used]. Boulder, Colorado USA. NASA National Snow and Ice Data Center Distributed Active Archive Center. 
Immerzeel, W.W., van Beek, L.P.H. and Bierkens, M.F.P., 2010. Climate Change Will Affect the Asian Water Towers. Science, 328(5984): 1382-1385. DOI:10.1126/science.1183188.

Liu, J. and Chen, R., 2011. Studying the spatiotemporal variation of snow-covered days over China based on combined use of MODIS snow-covered days and in situ observations. Theor. Appl. Climatol. , 106(3): 355-363. DOI:10.1007/s00704-011-0441-9.

Maskey, S., Uhlenbrook, S. and Ojha, S., 2011. An analysis of snow cover changes in the Himalayan region using MODIS snow products and in-situ temperature data. Clim. Change 108(1): 391. DOI:10.1007/s10584-011-0181-y.

Mountain Research Initiative EDW Working Group, 2015. Elevation-dependentwarming in mountain regions of the world. Nat. Clim. Change 5, 424-430.

Qiu, J., 2008. China: The third pole. Nature, 454(7203): 393-396.

Räisänen, J., 2008. Warmer climate: less or more snow? Clim. Dyn. , 30(2): 307-319. DOI:10.1007/s00382-007-0289-y.

Ruddiman, W. and Kutzbach, J., 1991. Plateau uplift and climatic change. Sci. Am. , 264(3): 66-75.

Snehmani, Dharpure, J.K., et al., 2016. Analysis of snow cover and climatic variability in Bhaga basin located in western Himalaya. Geocarto International, 31(10): 1094-1107. DOI:10.1080/10106049.2015.1120350.

Wang, J. and Li, S., 2006. Effect of climatic change on snowmelt runoffs in mountainous regions of inland rivers in Northwestern China. Science in China Series D: Earth Sciences, 49(8): 881-888. DOI:10.1007/s11430-006-0881-8.

Yao, T. et al., 2012. Third Pole Environment (TPE). Environmental Development, 3(Supplement C): 52-64. DOI:https://doi.org/10.1016/j.envdev.2012.04.002.

Zhang, Y., Li, B. and Zheng, D., 2002. A discussion on the boundary and area of the Tibetan Plateau in China. Geographical Research, 21(1): 1-8. 